\title{
Avaliação da implantação do planejamento estratégico em uma universidade pública: barreiras, facilitadores e eficácia
}

Evaluation of the implementation of strategic planning

in a public university: barriers, facilitators and effectiveness

\author{
Junia Maria Zandonade Falqueto ${ }^{1}$ \\ ${ }^{1}$ Universidade de Brasília | Faculdade de Economia, Administração, Contabilidade e Gestão \\ | Programa de Pós-Graduação em Administração \\ Brasília | DF | Brasil. Contato: jufalqueto@gmail.com \\ http://orcid.org/0000-0003-0074-941X
}

\author{
Valmir Emil Hoffmann ${ }^{2}$ \\ ${ }^{2}$ Universidade de Brasília | Faculdade de Economia, Administração, Contabilidade e Gestão \\ | Programa de Pós-Graduação em Administração \\ Brasília | DF | Brasil. Contato: ehoffmann@unb.br \\ http://orcid.org/0000-0002-8977-8454
}

Éverton Luís Pellizzaro de Lorenzi Cancellier ${ }^{3}$

${ }^{3}$ Universidade do Estado de Santa Catarina | Centro de Ciências da Administração e

Socioeconômicas | Departamento de Administração Empresarial

Florianópolis | SC | Brasil. Contato: everton.cancellier@udesc.br

http://orcid.org/0000-0002-2634-4763

\author{
Newton da Silva Miranda Júnior ${ }^{4}$ \\ ${ }^{4}$ Universidade de Brasília | Faculdade de Economia, Administração, Contabilidade e Gestão | \\ Programa de Pós-Graduação em Administração \\ Brasília | DF | Brasil. Contato: newtondasmjr@gmail.com \\ http://orcid.org/0000-0002-2876-4016
}

Resumo: O planejamento estratégico, embora difundido devido as vantagens proporcionadas às organizações, encontra dificuldades para ser implantado em ambientes dinâmicos e complexos, como os das instituições de ensino superior. Todavia, há fatores que incidem como facilitadores a essa implantação, auxiliando organizações a alcançarem eficácia. Nesse contexto, o presente artigo objetivou avaliar o processo de planejamento estratégico implantado em uma universidade pública brasileira. Buscou-se identificar as barreiras e os facilitadores, assim como o alcance da eficácia do planejamento estratégico. Para tanto, foram realizadas entrevistas semiestruturadas junto a gestores que atuam diretamente com o planejamento. Para definir o número de participantes da pesquisa, utilizou-se a saturação teórica. Entre as barreiras mais expressivas encontradas, citam-se a comunicação distorcida entre as unidades internas e ausência de sintonia entre o que é planejado e o que é realizado. $\mathrm{O}$ apoio da alta administração obteve destaque como facilitador ao processo. Por fim, concluiu-se que o planejamento estratégico é viável e é benéfico à Universidade, entretanto não se pode afirmar que ele esteja implantado de forma eficaz em todos os setores da instituição.

Palavras-chave: Planejamento estratégico. Gestão universitária. Universidade pública.

Abstract: Although advertised as providing benefits to organizations, strategic planning is struggling on its implementation in complex and dynamic environments, such as the higher education institutions. However, there are factors that facilitate this deployment, helping organizations achieve effectiveness. In this context, this paper aims to assess the strategic plan implemented at a Brazilian Public University. In addition, we sought to identify barriers and facilitators, as well as the extent of the effectiveness of 
strategic planning. Therefore, semi-structured interviews were conducted with managers of the institution who work directly with planning. The number of participants was defined based on the theoretical saturation technique. Among the most significant barriers to the implementation of strategic planning are the gaps in communication between the internal units and the lack of concordance between what is planned and what is done. The support of top management was featured as an important facilitator to the process. Finally, we concluded that strategic planning is feasible and beneficial to the University, but.the effective deployment was not detected in all sectors of the institution.

Key words: Strategic planning. University management. Public university.

DOI: http://dx.doi.org/10.1590/S1414-40772019000200002

Este é um artigo publicado em acesso aberto (Open Access) sob a licença Creative Commons Attribution Non-Commercial, que permite uso, distribuição e reprodução em qualquer meio, sem restrições desde que sem fins comerciais e que o trabalho original seja corretamente citado. https://creativecommons.org/licenses/by-nc/4.0/

Recebido em: 17 de novembro de 2017 Aprovado em: 23 de junho de 2019

\section{Introdução}

As organizações estão inseridas em ambientes instáveis e mutáveis, o que gera a necessidade de novos formatos organizacionais, bem como a adoção de novos modelos de gestão. A substituição do planejamento tradicional em favor do planejamento estratégico é um exemplo, haja vista que para lidar com a incerteza ambiental, não é suficiente apenas extrapolar as tendências do passado, é preciso definir missão, objetivos, metas e alternativas estratégicas com a atenção voltada às modificações ambientais (ARAÚJO, 1996).

Não apenas em organizações com fins lucrativos, mas também em governos, organizações públicas e organizações privadas sem fins lucrativos, o planejamento estratégico tem se mostrado uma ferramenta eficaz à boa gestão. Neste sentido, Bryson (2010) destaca o papel relevante que o planejamento estratégico desempenha em organizações que prestam serviços públicos, a exemplo de instituições de ensino superior (IES). A adoção de gestão estratégica tem se tornado recorrente no âmbito de IES de vários países frente ao desafio - cada vez mais em voga - atribuído a seus dirigentes de torná-las mais ativas e empreendedoras na sociedade (DEGN, 2014).

Nessa linha, o planejamento estratégico deve ser compreendido como um processo dinâmico, sistêmico, coletivo, participativo e contínuo para a determinação dos objetivos, estratégias e ações e, por isso, deve estar embasado nos problemas ou desafios da organização. Entre os benefícios proporcionados por um plano estratégico, citam-se: a maior sistematização nas operações, o aumento da racionalidade nas decisões, a redução dos riscos e maiores possibilidades de alcance dos objetivos previstos, elevando-se a eficiência, eficácia e efetividade nos processos organizacionais (MATIAS-PEREIRA, 2011; REZENDE; 2011). 
Outros benefícios identificados pela aplicação de boas práticas de planejamento estratégico no setor público consistem na promoção de significativas mudanças organizacionais, aumento do desempenho, pensamento sistemático sobre o futuro e agregação de valor no serviço público (POISTER, 2010).

A despeito dos benefícios já elucidados na literatura, ainda é desafiador para as universidades a tentativa de implantar a sistemática de planejamento estratégico. Entre os entraves, encontram-se a dispersão do poder, a ambiguidade dos objetivos, a descentralização das decisões em conjunto com a pouca coordenação e controle das tarefas e a falta de estrutura que facilite a implantação de estratégias (BALDRIDGE, 1971; MINTZBERG, 2003; MURIEL, 2006; MORITZ et al., 2012; FALQUETO, 2012).

Em consequência desses percalços e de outras peculiaridades das instituições de ensino superior (IES) relacionadas a estrutura, funcionamento e área de atuação, os modelos de planejamento estratégico aplicados com sucesso em outras formas de organização não podem ser transferidos integralmente para as IES, implicando dizer que universidades não devem ser vistas pela mesma ótica das demais iniciativas empresariais (BALDRIDGE, 1971; MEYER JUNIOR, 1988).

Por conseguinte, a implantação do planejamento estratégico no âmbito das universidades ainda é considerado um desafio (REZENDE, 2011), principalmente quando se busca colocá-la como prioridade na agenda universitária sugerindo um esforço participativo de toda a sua comunidade - gestores, professores, estudantes e técnicos. O desafio é ainda maior às universidades públicas por possuírem o dever de garantir a eficiência e qualidade na utilização dos recursos provenientes da sociedade (GRATERON, 1999).

Inserido nessa lacuna, o objetivo deste estudo é avaliar a implantação do planejamento estratégico em uma universidade pública brasileira - a Universidade de Brasília (UnB). Para tanto, foram identificas as barreiras e facilitadores ao processo e, por conseguinte, verificada a eficácia da implantação do planejamento estratégico em departamentos da IES. Por eficácia de uma ação ou programa, entende-se a relação entre os resultados obtidos e os objetivos pretendidos conforme Marinho e Façanha, 2001.

\section{Referencial Teórico}

\subsection{Planejamento Estratégico nas Instituições de Ensino Superior}

As instituições de ensino superior, quer seja por força da legislação quer seja pela busca de otimização da gestão, adotam o planejamento estratégico por considerá-lo um instrumento 
primordial no desenvolvimento de uma instituição social moderna (REBELO, 2004). Entendido como uma forma participativa e contínua de se pensar a organização no seu presente e no seu futuro, o planejamento estratégico se tornou um recurso indispensável à tomada de decisão (RASMUSSEM, 1990; GALLAS, 2008; REZENDE, 2011).

As instituições de ensino superior são caracterizadas pela sua estrutura complexa e multifuncional (BALDRIDGE, 1971, 1977, 1983; WEICK, 1983; MEYER JUNIOR, 1988, 2005; ARAÚJO, 1996; HARDY; FACHIN, 2000) voltadas à transmissão e produção do conhecimento agregado, sendo esse o principal produto fornecido por elas. Dessa forma, a qualidade do produto final depende tanto da instituição quanto do aluno. As condições prévias de cada indivíduo que ingressa num curso superior são diferentes, assim como a participação e o resultado final, implicando, dessa maneira, num produto difícil de ser mensurado (MEYER JUNIOR, 1991).

Ainda que preserve certa independência no âmbito acadêmico, as instituições de ensino superior não estão imunes às ações do ambiente externo, sobretudo no que se refere a decisões administrativas (ESTRADA, 2000). Assim, o planejamento estratégico deve proporcionar sustentação metodológica para que se estabeleça a melhor direção a ser seguida pela organização, visando a otimização do grau de interação com o ambiente (OLIVEIRA, 2009).

A identificação de ameaças e a consequente minimização de surpresas advindas do ambiente externo são possibilitadas por intermédio da gestão estratégica. Em outras palavras, no intuito de enfrentar a turbulência e garantir a sustentabilidade organizacional, uma alternativa é a prospecção de ambientes externos e não somente a compreensão deles num dado momento estático, seguida de um conjunto de ações de planejamento e gestão (CASTRO, 2005; ATHANÁZIO, 2010; MATIAS-PEREIRA, 2011).

Dessa forma, pode-se admitir que o planejamento estratégico é uma ferramenta que propicia obter vantagens sobre os competidores e permite identificar oportunidades. Deve ser elaborado por meio de diferentes e complementares técnicas administrativas com o total envolvimento das pessoas de dentro da organização e, por vezes, de pessoas externas. No contexto de organizações públicas, tal como as universidades federais, é relevante priorizar estratégias focadas na atividade do bem comum e vinculá-las às necessidades dos cidadãos e aos anseios da sociedade. De forma geral, no setor público, as estratégias relacionam-se à primazia ou excelência na prestação do serviço público, ao atendimento à sociedade, ao desenvolvimento de questões sociais e sustentáveis e à transparência (REZENDE, 2011). Sob o enfoque do modelo gerencial na administração pública - que passou a dar maior ênfase aos conceitos de eficiência, eficácia e efetividade governamental (FALQUETO; FARIAS, 2013) - 
as práticas do planejamento estratégico passaram a ser mais consistente e monitoradas nas instituições públicas brasileiras (MARCELINO; MATIAS-PEREIRA; BERBET, 2008).

\subsection{A implantação do planejamento estratégico em Universidades Públicas}

A importância de qualquer planejamento estratégico, a par da qualidade do seu conteúdo, está na sua praticidade e viabilidade de implantação. Afinal, o planejamento só adquire significado ao vincular-se à ação organizacional (MEYER JUNIOR, 1988; ARAÚJO, 1996; REZENDE, 2011). Entretanto, esse processo é dificultado pela própria natureza multidisciplinar das universidades, que são gestoras de recursos intelectuais, que geram e disseminam conhecimento, propagam debates e possuem objetivos extensos e complexos quando comparados a outras organizações (MORITZ et al., 2012). O planejamento estratégico de universidades vai além de uma metodologia ou de um processo técnico e implica em nova postura organizacional. Na prática, o esforço do planejamento nas IES exige dos gestores habilidade para lidar com aspectos subjetivos e intuitivos presentes na gestão universitária (MEYER JUNIOR, 1988, 1991, 2005; ESTRADA, 2000).

Portanto, a metodologia do planejamento estratégico em universidades deve levar em consideração que se trata de um sistema complexo no qual adaptações específicas serão necessárias. $\mathrm{O}$ ambiente externo possui papel relevante nesse contexto, posto que as instituições de ensino superior estão inseridas no macrossistema nação e sua missão depende dos objetivos nacionais, dos recursos disponíveis, das políticas industriais, tecnológicas, culturais e educacionais do país (BODINI, 1998). Assim, a implantação do planejamento estratégico em universidades lida com um exercício intelectual que combina criatividade e racionalidade, requer visão e liderança e tem implicações no comportamento e nas formas de se trabalhar (ESTRADA, 2000).

O Ministério da Educação - MEC, por meio da implantação do Sistema Nacional de Avaliação da Educação Superior - SINAES em 2004, constatou a necessidade de incluir, como parte integrante do processo avaliativo das universidades brasileiras, o seu planejamento estratégico, sintetizado no que se convencionou denominar de Plano de Desenvolvimento Institucional - PDI. Grande parte das instituições de ensino superior brasileiras, com a finalidade de atender a essas demandas, elaboraram um PDI compatível com sua realidade e com a complexidade do sistema no qual estão inseridas, buscando otimizar os recursos disponibilizados pelos governos e, com isso, atender às demandas da sociedade por uma administração eficiente. 
Conforme diretrizes para a elaboração do PDI, o plano estratégico deve ser feito de forma livre, sem deixar de contemplar os eixos temáticos essenciais. Deve, também, ser o documento institucional que representa a formalização do planejamento em universidades, abrangendo um período de cinco anos, contemplando, além do já mencionado, o cronograma e a metodologia de implantação dos objetivos, metas e ações da instituição e, quando pertinente, o orçamento. Assim, além de orientar as ações futuras, o PDI torna-se um instrumento legal para a aferição da qualidade da gestão universitária (BRASIL, 2006).

Deve-se notar que implantar uma nova estratégia sempre requer algum grau de mudança. Em alguns casos, a mudança ocorre de forma ampla e institucional, já em outros, é parcial e localizada, podendo envolver transformações na estrutura, nas pessoas e/ou nos processos organizacionais (FERNANDES; BERTON, 2005). Desta forma, quando a organização se propõe a implantar algo novo no campo estratégico, deve reconhecer, principalmente, as mudanças que ocorreram em nível de estrutura, tecnologia, processos e cultura organizacional. Segundo Matias-Pereira (2011), trata-se de atenção a aspectos “interdependentes que se apresentam interligados e se reforçam mutualmente" (MATIASPEREIRA, 2011, p. 135).

Por fim, a partir do cenário exposto, concorda-se com Estrada (2000), Muriel (2006) e Athanázio (2010), ao afirmarem que não existe uma única forma ou padrão de formulação e implantação do planejamento estratégico nas universidades, dada sua alta complexidade. Qualquer que seja a abordagem adotada, esta irá exigir dos gestores mais do que o domínio de habilidades técnicas ou mesmo de competências no trato dos interesses dos indivíduos e grupos envolvidos na gestão de IES.

\section{Metodologia}

A pesquisa é descritiva com abordagem qualitativa. Empregou-se o estudo de caso em uma universidade pública brasileira, a Universidade de Brasília, operacionalizado por meio de pesquisa documental e entrevistas semiestruturadas. Entre as justificativas para a escolha da IES, cita-se a expressividade dela perante as demais IES brasileira, sendo a sexta maior universidade pública em termos de número de alunos matriculados, conforme dados de 2016. Quanto ao aspecto temporal dos dados utilizados na pesquisa, o recorte considerou o momento em que a coleta de dados foi iniciada, no primeiro trimestre de 2012.

Os dados primários foram coletados a partir de entrevistas semiestruturadas de respostas abertas junto a gestores da instituição engajados com as atividades de planejamento estratégico. 
O cargo, o tempo de engajamento com planejamento estratégico e o tempo de vínculo com a universidade em questão foram considerados na escolha dos participantes e são informados no quadro 1.

Para determinar a ordem das unidades participantes do estudo, realizou-se um sorteio, considerando as características de uma amostra probabilística estratificada, ou seja, na qual a população é composta por estratos bem definido e cuja possibilidade de participação é a mesma para cada unidade (RICHARDSON, 1999). Assim, separaram-se as unidades administrativas e acadêmicas e realizou-se um sorteio, obtendo-se duas listas: uma para as unidades administrativas e outra para as unidades acadêmicas. As entrevistas ocorreram de forma intercalada entre as duas listas, respeitando-se a ordem do sorteio. Esse critério foi aplicado para evitar que um dos estratos pudesse ter um peso maior nos resultados do estudo.

Somou-se em 16 o número de participantes entrevistados, sendo que esse quantitativo foi definido através de critérios da técnica de saturação teórica, conforme Strauss e Corbin (2008). Nessa técnica, o fechamento amostral é operacionalmente definido com a suspensão da coleta de novos dados quando as informações já obtidas passam a apresentar, na avaliação do pesquisador, certa redundância ou repetição, não sendo considerado produtivo persistir na coleta de dados. Quaisquer dados novos apenas se somariam, de maneira mínima, às variações dos padrões já coletados (FONTANELLA; JANETE; TURATO, 2007). A seguir, apresentamse os perfis dos participantes da pesquisa.

\section{Quadro 1- Perfil dos gestores particiantes da pesquisa}

\begin{tabular}{|c|c|c|c|}
\hline $\begin{array}{c}\text { Identificação } \\
\text { da Entrevista }\end{array}$ & Cargo & $\begin{array}{c}\text { Tempo de engajamento com } \\
\text { planejamento estratégico }\end{array}$ & $\begin{array}{c}\text { Tempo de vínculo } \\
\text { com a organização }\end{array}$ \\
\hline E1 & Assessor técnico & 4 anos & 28 anos \\
\hline E2 & Diretor & 3 anos & 4 anos \\
\hline E3 & Analista de Planejamento & 3 anos & 2 anos \\
\hline E4 & Administrador & 1 ano e 6 meses & 30 anos \\
\hline E5 & Diretor & 1 ano & 20 anos \\
\hline E6 & Diretor & 5 anos & 25 anos \\
\hline E7 & Vice-Diretor & 2 anos & 30 anos \\
\hline E8 & Diretor & 6 anos & 16 anos \\
\hline E9 & Diretor & 3 anos e 6 meses & 18 anos \\
\hline E10 & Diretor & 4 anos e 6 meses & 18 anos \\
\hline E11 & Diretor & 1 ano & 18 anos \\
\hline E12 & Pró-Reitor & 2 anos & 23 anos \\
\hline E13 & Diretor & 6 ano e 2 meses & 10 anos \\
\hline E14 & Gestor de TI & 2 anos e 4 meses & \\
\hline E15 & Diretor & Diretor &
\end{tabular}

Fonte: elaborado pelos autores 
Para a análise e tratamento dos dados, adotou-se a análise de conteúdo conforme Bardin (2006). Norteado pela categorização apriorística, foram definidas três categorias à luz da literatura, as quais são informadas no quadro 2, o qual apresenta também a relação entre os objetivos específicos do artigo e as categorias determinadas, bem como as referências pesquisadas.

\section{Quadro 2 - Relação entre objetivos e categorias criadas}

\begin{tabular}{|c|c|c|}
\hline Objetivos Específicos & Categorias & Referências \\
\hline $\begin{array}{c}\text { Descrever o processo } \\
\text { de planejamento estratégico } \\
\text { implantado na UnB }\end{array}$ & $\begin{array}{c}\text { Processo de } \\
\text { planejamento } \\
\text { estratégico na } \\
\text { UnB }\end{array}$ & $\begin{array}{c}\text { Documentos institucionais; Mintzberg, Lampel, } \\
\text { Ahlstrand (2000); Trigueiro (1999); Meyer Junior } \\
(1988 ; 2005)\end{array}$ \\
\hline $\begin{array}{c}\text { Identificar barreiras e } \\
\text { facilitadores à implantação do } \\
\text { planejamento estratégico na } \\
\text { Universidade }\end{array}$ & $\begin{array}{c}\text { Barreiras e } \\
\text { facilitadores }\end{array}$ & $\begin{array}{c}\text { Araújo (1996); Baldridge (1971); Muriel } \\
\text { (2006);Moritz et al. (2012);Ansoff, McDonnell } \\
\text { (1993);Hardy, Fachin (2000); Meyer Junior (1988); } \\
\text { Weick (1983), Wrigt; Kroll; Parnell (2011) }\end{array}$ \\
\hline $\begin{array}{c}\text { Verificar a eficácia da } \\
\text { implantação do planejamento } \\
\text { estratégico na instituição }\end{array}$ & Eficácia & $\begin{array}{c}\text { Araújo (1996); Trigueiro (1999); Hardy; Fachin } \\
\text { (2000);Wrigt; Kroll; Parnell (2011); Meyer Junior } \\
\text { (1988); Motta (2002); Bryson (1988); Ansoff,; } \\
\text { McDonnell (1993) }\end{array}$ \\
\hline
\end{tabular}

Fonte: elaborado pelos autores

Para cada categoria, utilizou-se a análise de conteúdo com o intuito de classificar as informações coletadas nas entrevistas e promover a interpretação à luz da teoria. Conjugado a isso, conforme salientado, utilizou-se o método de saturação teórica, a fim de indicar o ponto da coleta de dados no qual as informações começaram a ser repetitivas e pouco acrescentariam ao material já obtido, não contribuindo de maneira relevante para os resultados (BARDIN, 2006; FONTANELLA; JANETE, TURATO, 2007; THIRY-CHERQUES, 2009). Para cada entrevistado, criou-se um quadro com a distinção de elementos novos e elementos reiterados, conforme exemplificado nos quadros 03,04 e 05 a seguir.

Quadro 3: Análise da entrevista 1 com identificação dos primeiros elementos

\begin{tabular}{|ll|}
\hline \multicolumn{1}{|c|}{ Entrevista 1 } \\
\hline \multicolumn{2}{|c|}{ Identificação dos primeiros elementos Categorias Barreiras e Facilitadores } \\
\hline 1. & Problemas com a comunicação interna \\
\hline 2. & Falta de participação na elaboração do Planejamento Estratégico \\
\hline 3. & Falta de recursos tecnológicos \\
\hline 4. & Falta de cultura de planejamento \\
\hline 5. & Docentes não preparados para atuar em cargos administrativos \\
\hline 6. & Falta de apoio da alta gestão \\
\hline
\end{tabular}

Fonte: elaborado pelos autores 


\section{Quadro 4: Análise da entrevista 2 com inclusão de novos elementos}

e confirmação daqueles já levantados

\begin{tabular}{|ll|}
\hline \multicolumn{1}{|c|}{ Contrevista 2 } \\
\hline \multicolumn{1}{|c|}{ Confirmou 4 elementos e incluiu 3 Categorias Barreiras e Facilitadores } \\
\hline \multicolumn{1}{|c|}{ REITEROU } \\
\hline 1. & Problemas com a comunicação interna \\
\hline 2. & Falta de participação na elaboração do Planejamento Estratégico \\
\hline 3. & Falta de recursos tecnológicos \\
\hline 4. & Docentes não preparados para atuar em cargos administrativos \\
\hline & \\
\hline 5. & Alta rotatividade de pessoal administrativo \\
\hline 6. & Baixo nível de qualificação dos corpo técnico-administrativo \\
\hline 7. & Falta de articulação entre o planejamento e o orçamento \\
\hline
\end{tabular}

Fonte: elaborado pelos autores

\section{Quadro 5: Análise da entrevista 3 com inclusão de novos elementos e confirmação daqueles já levantados}

\begin{tabular}{|ll|}
\hline \multicolumn{1}{|c|}{ Contrevista 3 } \\
\hline \multicolumn{2}{|c|}{ Confirmou 4 elementos e incluiu 1 Categorias Barreiras e Facilitadores } \\
\hline 1. & REITEROU \\
\hline 2. & Falta de participação na elaboração do Planejamento Estratégico \\
\hline 3. & Falta de cultura de planejamento \\
\hline 4. & Falta de articulação entre o planejamento e o orçamento \\
\hline \multicolumn{2}{c}{ INCLUIU } \\
\hline 5. & Alta interdependência entre as unidades \\
\hline
\end{tabular}

Fonte: elaborado pelos autores

Com relação à saturação de respostas, os resultados estão apresentados em termos do ponto de saturação, conforme tabela 1 . Na primeira linha consta o número da entrevista, na primeira coluna, estão as categorias pesquisadas e nas demais células foram atribuídos o valor de 0 (zero) para indicar que não foi encontrada qualquer nova informação e 1 (um) para informar que há nova informação na respectiva entrevista. Na entrevista E12, verificou-se que, para ambas as categorias, não surgiram novas informações, fato confirmado com a realização de novas entrevistas, sendo que para a categoria Barreiras e Facilitadores, a saturação o correu na E9. Thiry-Cherques (2009) recomenda que sejam feita, pelo menos, mais duas entrevistas após encontrado o ponto de saturação, para uma necessária confirmação. Neste estudo, optouse por realizar mais quatro entrevistas, a fim de se ter uma margem de segurança em relação à saturação das informações. 
Tabela 1: saturação teórica das respostas coletadas

\begin{tabular}{ccccccccccccccccc}
\hline Categorias & E1 & E2 & E3 & E4 & E5 & E6 & E7 & E8 & E9 & E10 & E11 & E12 & E13 & E14 & E15 & E16 \\
\hline $\begin{array}{c}\text { Barreiras / } \\
\text { Facilitadores }\end{array}$ & 1 & 1 & 1 & 1 & 0 & 1 & 0 & 1 & 0 & 1 & 1 & 0 & 0 & 0 & 0 & 0 \\
\hline Eficácia & 1 & 1 & 1 & 1 & 1 & 0 & 0 & 1 & 0 & 0 & 0 & 0 & 0 & 0 & 0 & 0 \\
\hline
\end{tabular}

Fonte: elaborado pelos autores

Também foi realizada pesquisa documental, por meio de consulta a documentos institucionais, a saber: Relatórios de Gestão de 2002 a 2012, Relatórios de Autoavaliação de 2005 a 2012, Manual de Planejamento (2007), Bases do Planejamento Estratégico e Tático dos Ciclos de 2006, Relatório de Avaliação da Gestão de Planejamento, Orçamento, Contabilidade e Finanças (2010) e atas dos Seminários de Planejamento de 2003 a 2010. Essa etapa foi especialmente relevante para a descrição das diretrizes do planejamento estratégico na organização.

\section{Resultados e Discussão}

\subsection{Análise do Planejamento Estratégico implantado na UnB}

A análise dos documentos cedidos pela organização aponta que o processo de planejamento da universidade estudada abrange os níveis estratégico, o tático e o operacional. Há um Sistema de Planejamento no qual estão contidas as propostas de atuação e as metas das unidades acadêmicas e administrativas. Esse sistema abrange os planos estabelecidos para um ciclo de planejamento quinquenal coincidindo o último ano do ciclo com o primeiro ano de um reitorado. É gerido e monitorado pela Diretoria de Planejamento, unidade integrante da PróReitoria de Planejamento e Orçamento da universidade. Como unidade gestora, essa diretoria constitui a instância técnica que orienta a operacionalização dos planos institucionais, propõe mudanças e assessora a administração superior no desenvolvimento das estratégias organizacionais.

Ao analisar a sistemática do planejamento da instituição, percebeu-se que as primeiras tentativas de se atuar de forma estratégica na organização são anteriores à obrigatoriedade de um plano institucional, ao contrário do que é defendido por Muriel (2006) e Moritz et al. (2012), que acreditam que somente após a Lei de Diretrizes e Bases da Educação Nacional (1996) é que as universidades brasileiras passaram a se preocupar com o planejamento estratégico. Apesar de não se encontrar documentação em grande quantidade sobre as primeiras experiências, verificou-se o registro de atividades que adotam o princípio de um plano estratégico em documentos anteriores à criação do sistema de planejamento, em 2002. 
Ocorre a participação das unidades no diagnóstico institucional, porém apenas algumas áreas consideradas estratégicas tomam parte na elaboração dos elementos do planejamento. $\mathrm{Ou}$ seja, o foco de atuação, a missão, a visão e as próprias estratégias de cada ciclo de planejamento são decididas a partir do debate entre setores que pertencem à cúpula estratégica, sugerindo que se trata de um processo top-down. Carvalho (2013), ao também estudar uma IES, corrobora esse resultado constatando a concentração de poder no âmbito de dirigentes em altos cargos institucionais.

Em desencontro a essas evidências, a literatura de gestão universitária converge quanto à importância da comunidade na elaboração das estratégias como um meio de auxiliar a formação de uma cultura favorável ao planejamento, de garantir sua continuidade e de evitar que a instituição se depare com barreiras corporativas e reacionárias durante a fase de implantação do plano estratégico (MEYER JUNIOR, 1988; ARAÚJO, 1996; PARK, 1997). Neste sentido, Buckland (2009) defende que a questão central está no fato de que em universidades as estratégias surgem e derivam do trabalho cotidiano em si, e não como uma atividade imposta pela cúpula.

Em estudo realizado na Universidade Federal de Tocantins, Nunes, Duarte e Pereira (2017) reforçaram essa conclusão ao defenderem a importância da participação de toda a comunidade acadêmica na construção do plano estratégico de forma que todas as pessoas envolvidas possam compreendê-lo, garantindo assim sua continuidade e resultados efetivamente positivos à universidade. Em contraposição, todavia, Carvalho (2013) constatou a situação paradoxal de que, apesar da demanda por participação no processo decisório na instituição de ensino superior, os representantes da comunidade universitária deixaram, por muitas vezes, de comparecer a importantes reuniões deliberativas.

Com relação os aspectos formais, verificou-se que a universidade possui métodos e instrumentos previstos para o acompanhamento e a avaliação do seu planejamento. Embora a eficácia de tais instrumentos não tenha sido avaliada neste estudo, ao se investigar as barreiras ao processo de implantação do planejamento, ficou constatado o desconhecimento, por parte dos gestores, da existência de uma prática de acompanhamento e avaliação do plano estratégico. Entretanto, um fator positivo a se considerar é a existência de um sistema de informação para o gerenciamento das atividades de planejamento. Quanto a esse ponto, Araújo (1996) alerta que não basta às instituições de ensino superior a utilização de um sistema de informação, uma vez que se faz necessário que ele seja eficiente, ágil e voltado para a atividade de planejamento - e não apenas para a de administração. 
Em relação à estrutura organizacional, Araújo (1996) defende que a manutenção de uma equipe permanente voltada ao planejamento - como ocorre na instituição objeto deste estudo é uma condição para sua institucionalização. Em contraponto, Estrada (2000) critica a centralização das atividades ligadas ao planejamento em apenas uma única pró-reitoria. Segundo esse autor, a centralização do planejamento inibe o envolvimento de outros segmentos institucionais e, consequentemente, compromete a etapa de implantação de estratégias. Não obstante, conforme sublinhado por Nunes, Duarte e Pereira (2017), a interface com outros segmentos internos à instituição revela-se importante considerando-se o fato de que o planejamento estratégico constitui um insumo à elaboração de importantes instrumentos de gestão no contexto de IES.

\section{Barreiras e Facilitadores à implantação do Planejamento Estratégico na UnB}

Foram levantadas dez barreiras e três facilitadores à implantação do planejamento estratégico conforme o discurso dos gestores entrevistados, sendo que, por vezes, percebeu-se durante a coleta dos dados que as barreiras confundem-se com os facilitadores, de tal forma que um facilitador se traduz em medidas de combate às barreiras identificadas. Por esse motivo, ambos - barreiras e facilitadores - passaram a ser representados na mesma categoria para os efeitos dos resultados desta pesquisa. A seguir, são discutidos as barreiras e os facilitadores encontrados, em ordem decrescente de expressividade, conforme as entrevistas realizadas.

A comunicação distorcida entre as unidades internas da instituição foi apontada por 14 gestores como uma barreira à implementação do planejamento estratégico na IES. Esse entrave pode ser traduzido, conforme os entrevistados, pela falta de publicidade das estratégias, pelo desconhecimento sobre as questões que envolvem o processo de planejamento estratégico e pela falta de interação entre as áreas. Distorções na comunicação interna podem representar empecilhos à gestão de organizações universitárias e à implantação de estratégias (ANSOFF; MCDONNELL, 1993; TRIGUEIRO, 1999; MURIEL, 2006), pressupondo-se que a comunicação organizacional é um processo natural das organizações e que por si só já representa um processo estratégico (CARDOSO, 2006).

A tecnologia e os sistemas de informação desempenham função relevante na implantação das estratégias, auxiliando à tomada de decisão e o acompanhamento de objetivos e metas (ARAÚJO, 1996; REZENDE, 2011). A despeito disso, as organizações acadêmicas, frequentemente, não possuem um ambiente propício à inovações e a introdução de novas tecnologias dá-se de maneira lenta (VIEIRA, E.; VIEIRA, M, 2004; MORTIZ et al., 2012). A 
universidade em questão conta com um sistema de informação específico voltado ao gerenciamento do planejamento. Entretanto, a ineficiência desse sistema quanto a precária integração com os demais sistemas foi apontada como uma barreira, conforme sublinhado por 12 entrevistados. Corroboram-se, dessa forma, as evidências encontradas por Kahveci et al. (2012), segundo as quais a atomização entre sistemas de informação dificulta a utilização deles de maneira estratégica, sendo uma problemática recorrente entre IES.

Outro entrave, apontado por dez gestores, refere-se à ausência de sintonia entre o que é planejado e o que é passível de ser implantado. De acordo com dados das entrevistas, uma das causas da inviabilidade da execução é o conteúdo das metas elaboradas pela administração superior que, em alguns casos, não são condizentes com a realidade da unidade para qual a meta foi pensada. Aspecto similar é relato por Poister (2010) ao criticar a abordagem top-down que limita a capacidade das unidades em desenvolver iniciativas para suas próprias necessidades e circunstâncias. Esse diagnóstico pode estar relacionado com a forma como o planejamento é elaborado, e também com a descentralização das decisões, com a desconexão entre as estruturas, com os objetivos difusos e com a falta de controle e acompanhamento do planejamento estratégico (ARAÚJO, 1996; MEYER JUNIOR, 1988; WEIK, 1983; BALDRIDGE, 1971; 1983; COHEN; MARCH; OSLEN, 1972).

Aspectos de natureza política enquanto barreira à implantação do planejamento estratégico foram apontados por oito gestores. Essa constatação também é verificada na literatura, a qual assevera que os aspectos políticos são comuns e acarretam entraves à gestão universitária (BALDRIDGE, 1971; PFEFFER; SALANCIK, 1974; ARAÚJO, 1996; HARDY; FACHIN, 2000), havendo disputa por poder e por recursos, com ações dependentes do alinhamento político e não do consenso (BALDRIDGE, 1971; PFEFFER; SALANCIK, 1974; ELLSTRÖN, 2007), interferindo, dessa maneira, na implantação do planejamento (BALDRIDGE, 1971).

Com relação às dificuldades ocasionadas pela interdependência entre as unidades, sabese que o planejamento envolve a organização como um todo, havendo a necessidade de cooperação entre os departamentos. Isto é, trata-se de um esforço sistêmico, dinâmico, coletivo e contínuo (ANSOFF; McDONNELL, 1993; REZENDE, 2011; WRIGT; KROLL; PARNELL, 2011). Quanto a esse fator, os resultados desta pesquisa deixam a entrever que as dificuldades acarretadas pela falta de apoio e parceria entre as áreas é um dado significativo para a implantação do processo de planejamento estratégico na instituição, uma vez que oito gestores alegam não ser possível concretizar parte dos objetivos devido à dependência que possuem de outras unidades. 
A falta de participação no processo de elaboração do planejamento foi outra constante nas entrevistas. O planejamento estratégico deve abranger todos os níveis hierárquicos a fim de que se crie uma cultura de se planejar constantemente (MEYER JUNIOR, 1988; ARAÚJO, 1996; ANSOFF; MCDONNELL, 1993; MORITZ et al., 2012). Citada por sete entrevistados, percebe-se que a falta de participação nas fases iniciais de discussão e elaboração do planejamento estratégico tem acarretado prejuízos à sua implantação. Nesse sentido, Mintzberg, Lampel e Ahlstrand (2000) asseguram que a implantação de ações estratégicas necessita focalizar um esforço coletivo da organização, uma vez que uma estratégia compartilhada irá orientar os esforços individuais em uma mesma direção.

A falta de cultura organizacional favorável ao planejamento também foi citada como barreira por dez gestores. Como consequência da falta de uma cultura propícia ao planejamento, instituições acadêmicas tendem a planejar mais para administrar crises do que para evitá-las (ARAÚJO; 1996; WRIGT; KROLL; PARNELL, 2011). No contexto da universidade estudada, constatou-se uma dualidade. Por um lado, unidades utilizam o planejamento de forma reativa, solucionando problemas imediatos, sem relacionar as ações com as metas e estratégias traçadas. Por outro lado, há unidades que se esforçam para utilizar o planejamento como ferramenta de gestão, demonstrando que o planejamento estratégico é possível, apesar das adversidades do contexto universitário.

A carência de pessoal qualificado para lidar com as atividades de planejamento, especialmente no nível operacional, foi outra barreira evidenciada. Citada por sete dos 16 entrevistados, esse resultado corrobora Bryson (1988) e Souza (2009) ao defenderem que a ausência da capacitação de pessoal gera um empecilho à implantação do plano estratégico, além de refletir a importância de treinamento e incentivo para a qualificação de pessoal nas IES.

Outra dificuldade, apontada por sete entrevistados, foi a falta de articulação entre o planejamento e o orçamento. Uma vez que o orçamento viabiliza o planejamento em termos de alocação de recursos financeiros, é preciso existir uma articulação entre ambos, de forma que as estratégias possam ser efetivamente desenvolvidas e os objetivos e metas possam ser alcançados (MEYER JUNIOR, 1988). A falta de integração entre as ferramentas que gerenciam os processos parece prejudicar ambos: no caso do planejamento estratégico, dificulta a implantação dos objetivos e metas, uma vez que não há uma fácil visualização e, por conseguinte, um controle eficaz dos recursos financeiros disponíveis para a sua materialização.

Cabe aqui uma observação: os entrevistados não falaram em restrições orçamentárias (o que poderia ser um resultado esperado pelas dificuldades encontradas nas relações com o poder público). De acordo com Araújo (1996), é comum não se compatibilizarem ações e recursos 
orçamentários nas universidades públicas, o que prejudica a efetividade do planejamento. Pode ser que a falta de articulação entre o planejamento e o orçamento cause dificuldades que sejam anteriores ou mais urgentes que a escassez de recursos financeiros, pois constatou-se que provoca insegurança e instabilidade na tomada de decisão nos setores.

Na sequência, a presença de gestores docentes não qualificados para atuar em gestão foi apontada por cinco entrevistados como um empecilho ao processo de planejamento estratégico. Em específico, os entrevistados atribuíram a presença de docentes em cargos administrativos como uma barreira. Sobre essa constatação, destaca-se que a formação docente não está voltada necessariamente à capacitação para o exercício de atividades administrativas, de que são exemplos o controle, a prestação de contas, a gestão organizacional e a supervisão (SALEME, 1988; ESTRADA, 2000; MURIAL, 2006). Nessa linha, a dificuldade de adaptação de docentes a cargos administrativos aliada à dificuldade de conciliação entre o exercício desses cargos e os afazeres acadêmicos também foram sublinhados por Baldridge (1977) e Saleme (1988) como barreiras à gestão estratégica em instituições de ensino superior.

Em relação aos facilitadores, os elementos mais citados foram: as ações relacionadas à comunicação institucional, ao treinamento e capacitação, à participação, à articulação entre o planejamento e o orçamento e às melhorias nos sistemas de informação. Cada um desses facilitadores foram citados por, pelo menos, cinco entrevistados. Além desses elementos, a criação de um ranking de desempenho e a busca por um maior entrosamento das equipes também foram citados em um número menor de entrevistas.

Nesse ponto, chama-se a atenção para a competição existente entre as unidades internas de universidades, diagnosticada nessa fase da pesquisa. Ao sugerirem a criação de um ranking de desempenho como um facilitador, os gestores, na verdade, demonstram que se importam com a performance do seu setor em comparação ao de seus pares. Outros estudos que também exploraram a temática do planejamento estratégico em universidades (CUNHA, 1995; ESTRADA,2000; MURIEL, 2006; ATHANÁZIO, 2010) não identificaram a rivalidade interna entre os setores como um fator de impacto ao planejamento estratégico. Já nesta pesquisa, percebeu-se que, além da disputa por recursos e por apoio político, conforme descrevem Baldridge (1971), Meyer Junior. (1988) e Araújo (1996), há também a rivalidade por status e por desempenho superior a de outros setores como um fator de impacto à implantação das estratégias. Entende-se que o acompanhamento sistemático do desempenho das unidades e sua publicização, pode ser uma oportunidade para as universidades melhorem a institucionalização do planejamento, desde que a alta gestão esteja atenta e aja para minimizar possíveis constrangimentos que poderão resultar em uma repercussão negativa ao processo. 


\subsection{Eficácia na implantação do Planejamento Estratégico na UnB}

As informações coletadas demonstraram que as unidades possuem desempenhos diferentes em relação à implantação dos objetivos traçados. Esse resultado está coerente com as características estruturais das IES encontradas na literatura. De acordo com alguns autores que também investigaram a administração universitária brasileira (ARAÚJO, 1996; TRIGUEIRO, 1999; HARDY; FACHIN, 2000; VIEIRA, E.; VIEIRA, M; 2004), o modelo de gestão das IES no Brasil permite às subunidades uma existência autônoma, frouxamente articuladas com a cúpula estratégica, com uma coordenação das atividades e com um poder ambíguo e disperso. Tal estrutura organizacional requer das universidades um esforço maior no alinhamento das suas estratégias (WRIGHT; KROLL; PARNELL, 2011).

Entre os 16 gestores entrevistados, dez afirmaram que a implantação do planejamento estratégico no seu setor de atuação foi ineficaz ou não realizada, os demais informaram que a implantação ocorreu de maneira eficaz. Tal resultado se assemelha ao verificado por Nauffal e Nasser (2012), que, ao investigar o planejamento estratégico em universidades, destacaram que a natureza colegiada da decisão implica em inabilidade em tomar decisões rápidas, resultando na realização de planos incompletos ou na solicitação de tempo adicional para concluir as atividades demandas pelo planejamento estratégico.

Dentre os motivos para a ineficácia percebida, os gestores mencionaram a falta de credibilidade do planejamento, a subjetividade na declaração das metas alcançadas e a ausência de acompanhamento e avaliação do processo de implantação como empecilhos para o alcance dos objetivos. Sobre a necessidade de avaliação do processo, Meyer Junior (1988) já ressaltava que o monitoramento deve ser uma atividade permanente pois afeta todas as fases do planejamento. Tal achado corrobora o obtido por Zhang (2014), que constatou a importância dos esquemas de implantação da estratégia em universidades australianas por meio indicadores chave de acompanhamento do desempenho nas suas variadas unidades.

\section{Considerações Finais}

Este estudo avaliou a implantação do planejamento estratégico em uma universidade pública brasileira - a Universidade de Brasília. Para tanto, a pesquisa foi direcionada por três objetivos específicos. Primeiro, descreveu-se, a partir de pesquisa documental, o processo de planejamento estratégico na organização. Em seguida, buscou-se identificar as barreiras e os facilitadores à implantação do planejamento estratégico no contexto institucional e, por fim, a eficácia do processo foi avaliada. 
A análise dos dados coletados possibilitou detectar que, na maior parte dos setores investigados, o planejamento estratégico acontece sob uma perspectiva botton-up na prática e não top-down como previsto na pesquisa documental realizada, o que sugere a existência de um problema de coordenação do processo na instituição. Em outras palavras, apesar de se tratar de um planejamento formalmente elaborado, instituído e gerenciado pela cúpula estratégica, há unidades que agem conforme seus próprios interesses, estando ou não alinhados com os objetivos e estratégias definidas pela administração superior.

Foram muitos os entraves à implantação do planejamento estratégico identificados, o que vem a confirmar a complexidade das instituições universitárias discutidas no referencial teórico. As barreiras relacionadas à comunicação interna obtiveram destaque por ter sido a problemática mais mencionada entre os entrevistados. As informações coletadas revelaram que, no contexto da instituição, as distorções na comunicação dificultam o planejamento estratégico, já que algumas unidades não chegam a tomar conhecimento das questões que envolvem as estratégias da instituição.

Em relação à eficácia, os resultados sinalizaram para um descompasso entre os setores. Percebeu-se que alguns utilizam o planejamento apenas por formalidade, realizando somente o que é obrigatório, sem a devida preocupação com a eficácia e o desempenho do processo. $\mathrm{Ou}$ seja, o planejamento aparenta estar dissociado da gestão. Nesse sentido, reforça-se que o planejamento estratégico deve fazer parte das atividades normais de gestão e não ser algo que se faz de vez em quando; deve constituir um processo vivo que envolva toda a comunidade universitária.

De forma geral, os resultados concebidos neste estudo indicam que há atitudes que devem ser tomadas para implantar o planejamento estratégico como um instrumento de gestão eficaz na organização estudada. Necessitam ser criadas e trabalhadas condições não apenas materiais, mas principalmente de legitimidade e de institucionalização do planejamento, pois sem a crença no instrumento dificilmente se avançará em termos de eficácia.

No entanto, há de se ressaltar que as dificuldades apontadas e a descoberta de que parte das unidades considera a implantação do planejamento ineficaz ou não realizada não devem significar a inviabilidade da adoção do planejamento estratégico no contexto universitário. Antes indicam a necessidade de repensar a metodologia do planejamento aplicada, de modo a criar condições objetivas para melhorar a eficácia do instrumento.

A principal limitação vivenciada diz respeito às dificuldades de acesso a documentação completa. Constatou-se, por exemplo, que, embora alguns documentos apontem a existência de seminários periódicos de avaliação do planejamento, não foi disponibilizada documentação 
relativa a esses eventos. Esse fato pode significar que tais atividades não ocorreram na universidade, apesar de documentos institucionais preverem a sua realização.

Como agenda de pesquisa, sugere-se ampliar a análise para outras IES, a fim de viabilizar comparações e ampliar os achados deste estudo. Recomenda-se também estudar a implantação do planejamento estratégico em instituições acadêmicas à luz da Teoria da Agência. Analisar o problema de agência que ocorre na gestão de universidades poderá aprofundar os resultados encontrados neste trabalho e produzir novos achados, especialmente no que diz respeito aos papéis da sociedade (principal) e da administração superior e professores (agente) na aplicabilidade de um plano estratégico.

\section{Referências}

ANSOFF, H. I.; McDONNELL, E. J. Implantando a administração estratégica. 2. ed. São Paulo: Atlas, 1993.

ARAÚJO, M. A. D. Planejamento estratégico: um instrumental à disposição das universidades? Revista de Administração Pública, Rio de Janeiro, n. 30, p. 74-86, jul./ago.1996.

ATHANÁZIO, M. M. Processo de planejamento estratégico em universidade pública: o caso da Universidade Federal do Pará, 2010. 153 f. Dissertação (Mestrado em Administração) - Universidade Federal do Pará, Natal, 2010.

BALDRIDGE, J. V. Power and conflict in the university. New York: John Wiley, 1971.

BALDRIDGE, J. V. Alternative model of governance in higher education. In: RYLEY, G. L.; BALDRIDGE, J. V. Governing academic organizations: new problems, new perspectives. Berkeley: McCutchan Publishng Corporation, 1977. p. 2-25.

BALDRIDGE, J. V. Organizational characteristics of colleges and universities. In:

BALDRIDGE, J. V.; DEAL, T. The dynamics of organizational change in educations.

California: McCutchan Publishing Corporation, 1983.

BARDIN, L. Análise de conteúdo. São Paulo: Edições 70, 2006.

BODINI, V. L. Planejamento Estratégico em Universidades. In: ENCONTRO NACIONAL DE ENGENHARIA DE PRODUÇÃO, 18, 1998. Anais [...]. Niterói: Universidade Federal Fluminense, 1998.

BRASIL. Decreto n. 5.773, de 09 de maio de 2006. Dispõe sobre o exercício das funções de regulação, supervisão e avaliação das instituições de educação superior e cursos superiores de graduação. Diário Oficial da União, Brasília, DF, 10 maio, 2006. 
BRYSON, J. M. A Strategic planning process for public and nonprofit organizations. Long Range Planning, Great Britain, v. 21, n. 1, p. 73-88, 1988.

BRYSON, J. M. The future of public and nonprofit strategic planning in the United States. Public Administration Review, USA, v. 10, n. especial, p. 255-267, 2010.

BUCKLAND, R. Private and public sector models for strategies in universities. British Journal of Management, London, v. 20, n. 4, p. 524-536, 2009.

CARDOSO, O. Comunicação empresarial versus comunicação organizacional: novos desafios teóricos. Revista de Administração Pública, Rio de Janeiro, v. 40, n. 6, p.11231144, 2006.

CARVALHO, R. F. Limites, possibilidades e desafios no processo de gestão e participação das IFES/UFT. Avaliação, Campinas; Sorocaba, v. 18, n. 2, p. 351-372, 2013.

CASTRO, A. G. Metodologia de planejamento estratégico das unidades do MCT. Brasília: Ministério da Ciência e Tecnologia, 2005.

COHEN, M. D.; MARCH, J. G.; OSLEN, J. P. A garbage cam model of organization choice. Administrative Science Quarterly, New York, USA, v. 17, p. 1-25, 1972.

CUNHA, C. J. C. A. Planejamento estratégico: uma abordagem prática. Florianopolis: NEST-UFSC, 1996.

DEGN, L. Sensemaking, sensegiving and strategic management in Danish higher education. Higher Education, USA, v. 69, n. 6, p. 901-913, 2014.

ELLSTRÖN, P. Quatro faces das organizações educacionais. Revista Brasileira de Política e Administração da Educação, Goiânia, v. 23, n. 3, p. 449-461, set./dez. 2007.

ESTRADA, R. J. S. Os rumos do planejamento estratégico na universidade pública: um estudo de caso na Universidade Federal de Santa Maria. 2000. 206f. Tese (Doutorado em Engenharia de Produção) - Centro Tecnológico, Universidade Federal de Santa Catarina, Florianópolis, SC, 2000.

FALQUETO, J. M. Z. Planejamento estratégico na UNB. 2012. 192 f. Dissertação (Mestrado em Administração) - Universidade de Brasília, Brasília, 2012.

FALQUETO, J. M. Z.; FARIAS, J. S. A trajetória e a funcionalidade da universidade pública brasileira. Revista GUAL, Florianópolis, v. 6, n. 1, p. 22-41, jan. 2013.

FERNANDES, B. H. R.; BERTON, L. H. Administração estratégica: da competência empreendedora a avaliação de desempenho. São Paulo: Saraiva, 2005.

FONTANELLA, B. J. B.; JANETE, R.; TURATO, E. R. Amostragem por saturação em pesquisas qualitativas em saúde: contribuições teóricas. Caderno Saúde Pública, Rio de Janeiro, p. 17-27, jan. 2007. 
GALLAS, J. C. Comportamento estratégico, ambiente organizacional e desempenho: um estudo com pequenas empresas de beleza estética. 2008. 87 f. Dissertação (Mestrado em Administração) - Universidade do Vale do Itajaí, Biguaçu, 2008.

GRATERON, I. R. Auditoria de gestão: utilização de indicadores de gestão no setor público. Caderno de Estudos, São Paulo, n. 21, maio/ago. 1999.

HARDY, C.; FACHIN, R. C. Gestão estratégica na universidade brasileira: teoria e casos. 2. ed. Porto Alegre: Editora Universidade, 2000.

KAHVECI, T. C. et al. Quality Assurance in Higher Education Institutions Using Strategic Information Systems. Procedia - Social and Behavioral Sciences, Elsevier (Science Direct), v. 55, n.5, p. 161-167, 2012.

DOI: $10.1016 /$ j.sbspro.2012.09.490

MARCELINO, G.; MATIAS-PEREIRA, J.; BERBERT, C. O. Gestão estratégica em ciência e tecnologia: avaliação de uma experiência de alinhamento estratégico no governo federal. In: MENDONÇA, G. M. Estudos contemporâneos em organização e gestão. São Luiz: Editora Universidade Estadual do Maranhão, 2008. p. 111-148.

MARINHO, A.; FAÇANHA, L; O. Programas sociais: efetividade, eficiência e eficácia como dimensões operacionais da avaliação. Brasília: IPEA, 2001.

MATIAS-PEREIRA, J. Administração estratégica: foco no planejamento estratégico. São Paulo: Atlas, 2011.

MEYER JUNIOR, A. Considerações sobre o planejamento universitário: mito e realidade. In: FINGER, A. P. (org.) Universidade: organização, planejamento e gestão. Santa Catarina: NUPEAU/UFSC, 1988.

MEYER JUNIOR, A. Planejamento estratégico: uma renovação na gestão das instituições universitárias. In: SEMINÁRIO: A ADMINISTRAÇÃO UNIVERSITÁRIA RUMO AO ANO 2000, 1991, Florianópolis: CPGA/UFSC, 1991.

MEYER JUNIOR, A. Planejamento Universitário: ato racional, político ou simbólico - um estudo de universidades brasileiras. Revista Alcance, Santa Catarina, v. 12, n. 13, p. 373-389, set/dez. 2005.

MINTZBERG, H. Criando organizações eficazes: estruturas em cinco configurações. 2. ed. São Paulo: Atlas, 2003.

MINTZBERG, H.; LAMPEL, J.; AHSLTRAND, B. Safári de estratégia: um roteiro pela selva do planejamento estratégico. Porto Alegre: Bookman, 2000.

MORITZ, M. O. et al. A implantação do Planejamento estratégico em organizações complexas: o caso da Universidade do Estado de Santa Catarina. Revista GUAL, Florianópolis, v. 5, n. 1, jan./abr, 2012.

MOTTA, P. R. Gestão contemporânea: a ciência e a arte de ser dirigente. Rio de Janeiro: Record, 2002. 
MURIEL, R. Plano de desenvolvimento institucional: análise do processo de implantação. Espírito Santo: Hoper, 2006.

NAUFFAL, D. I.; NASSER, R. N. Strategic planning at two levels: contrasting strategic planning processa at Qatar University (public) and Lebanese American University (private). Planning for Higher Educaton, USA, v. 40, n. 4, p. 32-39, 2012.

NUNES, E. B.; DUARTE, M. M.; PEREIRA, I. C. A. Planejamento e Avaliação Institucional: um indicador do instrumento de avaliação do SINAES. Avaliação, Campinas; Sorocaba, SP, v. 22, n. 2, p. 373-374, 2017. Disponível em: http://www.scielo.br/scielo.php?pid= S1414-40772017000200373\&script=sci_abstract\&tlng=pt. Acesso em: 13 nov. 2017.

OLIVEIRA, D. Planejamento estratégico. São Paulo: Atlas, 2009.

PARK, J. E. A Case study analysis of strategic planning in a continuing higher education organization. Thesis (PhD in Philosophy) - College of Education, Pennsylvania State University, Pennsylvania, 1997.

PFEFFER, J.; SALANCIK, G. R. Organizational decision making as a political process: the case of a university budget. Administrative Science Quarterly, Sage Publishing, v. 19, p. 135-151, 1974.

POISTER, T. H. The future of strategic planning in the public sector: linking strategic management and performance. Public Administration Review, USA, n. 10, p. 246-254, 2010 .

RASMUSSEM, U.W. Manual da metodologia do planejamento estratégico. São Paulo: Aduaneiras, 1990.

REBELO, L. M. B. A dinâmica do processo de formação de estratégias de gestão em universidades: a perspectiva da teoria da complexidade. 2004. 278 f. Tese (Doutorado em Engenharia de Produção) - Universidade Federal de Santa Catarina, Florianópolis, Santa Catarina, 2004.

REZENDE, D. A. Planejamento estratégico público ou privado: guia para projetos em organizações de governo ou de negócio. São Paulo: Atlas, 2011.

RICHARDSON, R. J. Pesquisa social: métodos e técnicas. 3. ed. São Paulo: Atlas, 1999.

SALEME. W. Planejamento universitário: um instrumento eficaz. In: CARVALHO, A. O. (orgs). Administração contemporânea. Belo Horizonte: UFMG, 1988.

SOUZA, I. M. Gestão das universidades federais brasileiras: uma abordagem fundamentada na gestão do conhecimento. 2009. 398 f. Tese (Doutorado em Engenharia e Gestão do Conhecimento) - Universidade Federal de Santa Catarina, Florianópolis, 2009.

STRAUSS, A.; CORBIN, J. Pesquisa qualitativa: técnicas e procedimentos para o desenvolvimento de teoria fundamentada. 2. ed. Porto Alegre: Artmed, 2008. 
THIRY-CHERQUES, H. R. Saturação em pesquisa qualitativa: estimativa empírica de dimensionamento. Revista Brasileira de Pesquisas em Marketing, São Paulo, v. 3, set. 2009.

TRIGUEIRO, M. G. S. Universidades públicas: desafios e possibilidades no Brasil contemporâneo. Brasília: Editora Universidade de Brasília, 1999.

VIEIRA, E.; VIEIRA, M. Funcionalidade burocrática nas universidades federais. Revista de Administração Contemporânea, Curitiba, v. 8, n. 2, p. 181-200, abr./jun. 2004.

WEICK, K. E. The presumption of logic in executive thought and action (prepared for the Symposium Functioning of the Executive Mind; Case Western Reserve University). In:

SRIVASTVA, S. (ed.). The Executive Mind. San Francisco: Jossey-Bass, 1983. p.221-243.

WRIGT, P.; KROLL, M. J.; PARNELL, J. Administração estratégica: conceitos. São Paulo: Atlas, 2011.

ZHANG, A. Learning strategic planning from Australian and New Zealand university experience. Chinese Education and Society, University of Michigan, Ann Arbor, USA, v. 47, n. 2, 2014. 